\title{
Power-Integrated Circuit Active Leakage Current Detector
}

\author{
M. F. Bulacio, T. A. González, G. Marinelli, R. Alonso, and H. E. Tacca \\ LABCATyP, Department of Electronics, Faculty of Engineering, University of Buenos Aires, Av. Paseo Colón 850, C1063ACV, \\ Buenos Aires, Argentina
}

Correspondence should be addressed to M. F. Bulacio, mbulacio@fi.uba.ar

Received 30 December 2011; Revised 28 March 2012; Accepted 29 March 2012

Academic Editor: Francesco Profumo

Copyright () 2012 M. F. Bulacio et al. This is an open access article distributed under the Creative Commons Attribution License, which permits unrestricted use, distribution, and reproduction in any medium, provided the original work is properly cited.

\begin{abstract}
Most of the failures of induction motors become insulation faults, causing a permanent damage. Using differential current transformers, a system capable of insulation fault detection was developed, based on the differential relay protection scheme. Both signal injection and fault detection circuitry were integrated in a single chip. The proposed scheme is faster than other existing protection and not restricted to protect induction motors, but several other devices (such as IGBTs) and systems. This paper explains the principle of operation of fault protection scheme and analyzes an integrated implementation through simulations and experimental results. A power-integrated circuit (PIC) implementation is presented.
\end{abstract}

\section{Introduction}

Nowadays, induction motors are the most frequently used drives for motion control systems in industrial applications [1]. The industry is particularly concerned about the failure of these devices since it could cause significant economical losses due to the stop of production for long time spans and the risk to the personal safety of the operators. Statistics show that annual down times of $0.5 \%$ to $4 \%$ may be expected [2].

The main causes of motor failure are the variation of the feeding phase voltages, mechanical overloads, and problems produced by inadequate or faulted electrical installations [35]. Other causes may include the aging of the motor or eventual adverse environmental conditions. Most of these events lead to an increase of the current and to a subsequent rise of motor temperature. An unacceptable overheating of the motor damages the insulation of the windings and puts the motor out of service [4-7]. High dv/dt, characteristic of PWM variable speed drives, is a source of further stress and deterioration of the insulation.

The objective of motor protection is to keep the mechanical and thermal conditions within the acceptable limits while ensuring the highest fault detection sensitivity.

In order to fulfill this objective, several protection and monitoring systems are introduced in the bibliography with a clear tendency to integrate them in the variable speed drives. The purpose of monitoring systems is to detect a failure in an early stage of its development, by checking some parameters such as parasitic capacitances and resistance or the dissipation factor, without letting the fault to cause irreversible damage to the machine or its driving devices. On the other hand, most protection methods detect a fault when it becomes severe. Monitoring can be classified as online or offline depending on whether the motor can be tested during normal operation or it must be disconnected first.

Offline maintenance analyses are performed every 3 to 6 years [8] and some of them require the motors to be fully unmounted. Other strategies use the inverter itself to inject signals so as to monitor sensitive components of the system [8]. Although this allows the user to test devices without the need of disassembly, the proposed strategies are suitable for monitoring components that deteriorate gradually to failure. Other components such as power semiconductor devices or insulation, which fail abruptly, cannot be monitored using these methods due to their offline nature.

On the contrary online methods are those used to monitor adjustable speed drive systems in a continuous fashion. They provide more accurate and reliable information about the state of the insulation and the remaining service life of the machine than the offline tests. Several online tests exist and can be classified as chemical or thermal monitoring, turns fault detection, and fault-to-ground circuit breakers [9]. While the first two seek the early detection of faults, the last is generally used to protect against severe phase-to-ground 


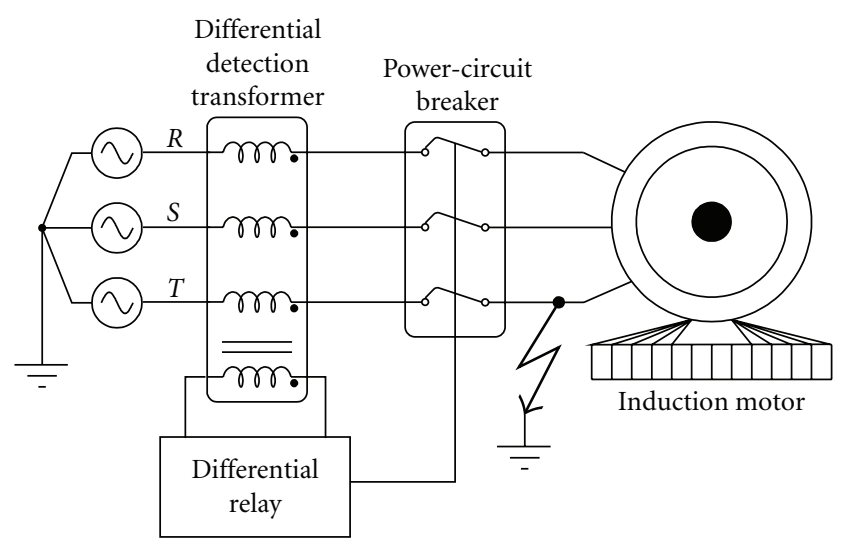

FIgURE 1: Differential protection scheme.

faults. Protection schemes such as the one presented in $[9,10]$ are very effective methods of detecting small incipient faults (turns fault).

The weakness of online monitoring methods like the one presented in [8-10], which measures voltages and currents to calculate state defining parameters, are its slow response and its imprecision under severe failure conditions.

Consequently, this paper presents the development of an integrated protection system, which follows the protection principle of a differential relay but detects the fault and trip in a few microseconds. Thus, it could be used to protect sensible power modules (e.g., IGBTs from a three-phase bridge), which usually need to be disabled before approximately $10 \mu \mathrm{s}$.

All the subsystems required in a modern adjustable speed drive are being developed at LABCATyP using Flash-based FPGA devices [11-13]. Thus, a phase-to-ground current protection circuit was implemented with the objective to protect both the motor and the power module. In contrast to other methods presented in the bibliography, it was mandatory to provide a fast detection response.

The possibility to test the performance of the leakage current protection subsystem was given by an integrated circuit design award. Moreover, this allows the future use of this IP together with the HDL IP developed $[12,13]$ in the past at LABCATyP to integrate a complete controller.

Although there are various chips with this functionality in the market [14], the novelty of this device lies in the possibility of detecting failures in very short time, as it treats the detected signal at hardware level.

It is shown that this system could be used as a preventive offline protection system and online monitoring of the homopolar current component to detect sudden insulation faults from phase to ground. Simulation and experimental results are presented in order to validate the functionality of the design.

\section{Line-to-Ground Insulation Fault Protection}

2.1. Basic Protection Scheme. A common protection scheme used in the industry is the one found in differential relays $[15,16]$. These devices switch the motor off whenever a zero sequence current in the feed lines appears. In home

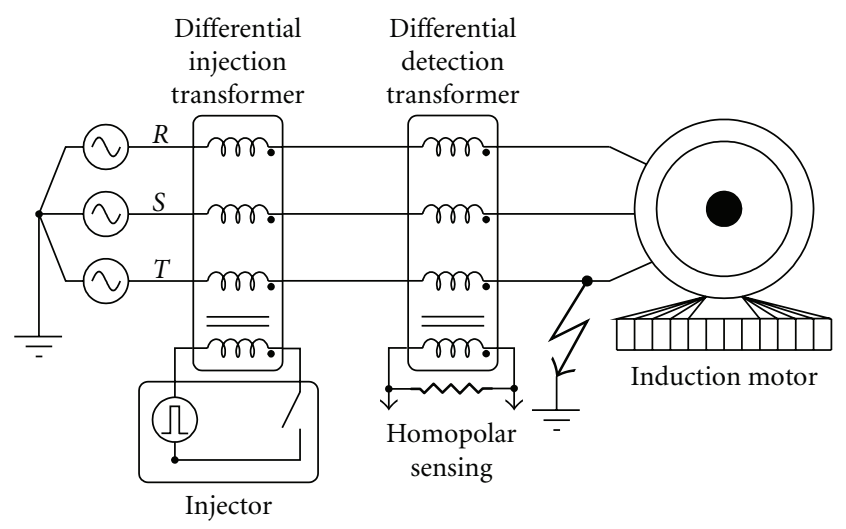

FIgURE 2: Injection and detection signal scheme.

appliances they are used to avoid the circulation of current levels that could be dangerous for the human body. The effects on humans depend on the value and duration of the fault current [17].

Differential protection systems are conceptually based on the property of single-phase and three-phase systems, which states that the sum of the line currents must be equal to zero. Thus, if a current flows into the earth, the device detects the residual current and it causes a trip.

The leakage current level which makes the device trip defines the sensitivity of this type of protection $(6 \mathrm{~mA}$ to several Amperes sensitivities are normally found in the market).

Three distinct parts constitute a differential protection: a differential sensor, a differential relay and a power circuit breaker. Figure 1 shows these parts and their connection in a simple real-life application.

The sensor is a transformer which adds the motor currents. If the currents do not add to zero, a voltage proportional to the residual current is induced in the secondary winding. The relay determines whether this voltage is enough to trip depending on the sensitivity of the protection. This sensitivity can be adjusted through an internal threshold which fixes the minimum current considered as a fault. The power circuit breaker should have an adequate breaking capability for the specific load and could be an electromagnetic switch or a solid-state device. Figure 1 depicts a shortto-earth event in which the homopolar current component produces an induced secondary voltage.

IEC 61008-1 standard establishes that differential breakers must trip when the value of the leakage current reaches from 50 to $100 \%$ of the selected sensitivity. The implementation of this type of protection by means of electronic devices allows the detection at $100 \%$ of the sensitivity, preventing erroneous trips.

2.2. Protection Scheme with Signal Injection. If the scheme shown in Figure 1 is built using small-core transformers, a failure could only be detected if high-frequency currents were to circulate the lines (e.g., between a PWM generator and the motor). In order to solve this problem without increasing the core size, an additional current transformer is used so as to provide the needed high-frequency signal (Figure 2). 


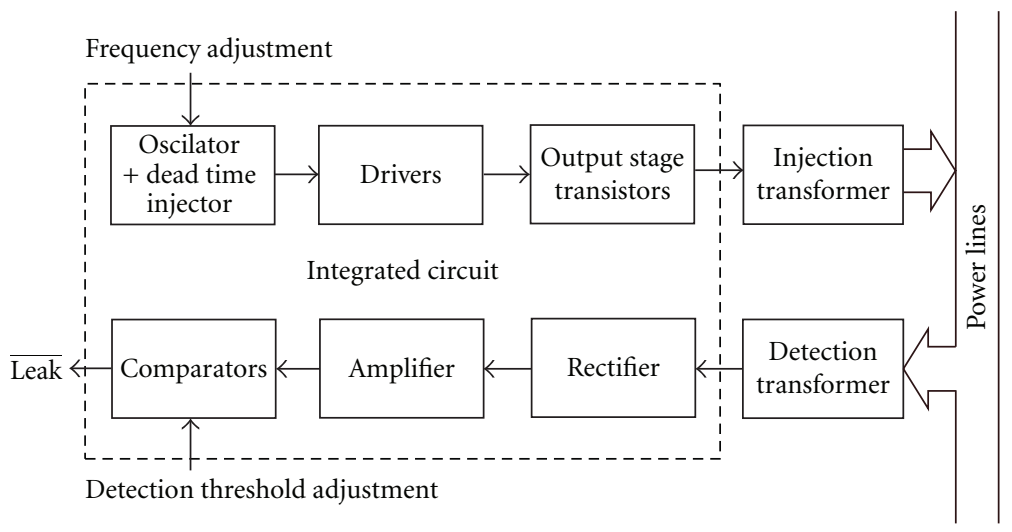

FIgURE 3: Block diagram of the integrated circuit.
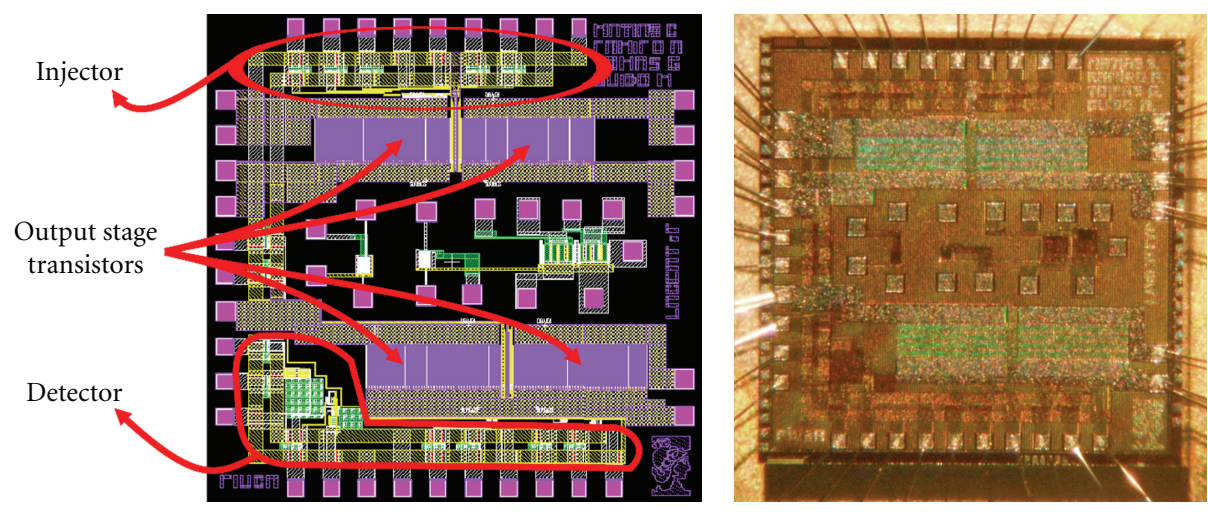

FIGURE 4: Layout and microscopic image of the integrated circuit.

The signal injection circuit will not produce a highfrequency circulating current as long as the motor does not have a neutral connection, which is the usual case. In this situation, the secondary of the differential current detection transformer presents no induced voltage. The signal will be effectively injected and detected when a ground or neutral fault occurs because only the homopolar current could produce a net flux in the transformer core to induce a detectable secondary voltage.

If the neutral terminal is accessible to the operator, both line-to-ground and line-to-neutral faults can be discriminated between each other by using two detection circuits and passing the neutral wire through one of the detection transformer cores.

2.3. Integrated Protection System. A circuit was developed in order to generate the high-frequency signal which is introduced on the power line through the injection differential transformer. On the other side, another circuit (designed to detect load insulation failures) processes the signal induced in the detection differential transformer.

Both circuits were integrated on a single die using the process XC06 of XFAB. The packaging was provided by APTASIC. Figure 3 shows a block diagram with the most important parts of the integrated circuit, and Figure 4 is a picture of the IC itself.
The oscillator generates the base frequency that is used to obtain two complementary command signals with dead time. They excite the push-pull-integrated output transistors, which are connected to the external differential injection transformer, in order to inject a high-frequency square signal to the power line.

A Schottky-based full diode bridge is connected at the differential detection transformer output to rectify the detected signal. This signal is amplified and then compared against an externally adjustable threshold, which determines the sensibility of the protection. Two separate comparators with configurable external thresholds were designed. The output of the amplifier must be connected externally to both comparators inputs. Then two external RC lowpass filters could be designed to offer low current/slow detection and a high current/fast leakage detection so as to provide protection to human life and power electronic devices, respectively. The connection of the fast filter detection is shown in Figure 8(a).

2.4. Simulations. In order to verify the circuit's correct functionality, simulations were made using XFAB design kit models. Figure 5 shows a simplified circuit including signal generation, signal detection, analog signal processing, and leakage model.

Under normal operation, without fault, the zero sequence current circulating through the power line is zero, 


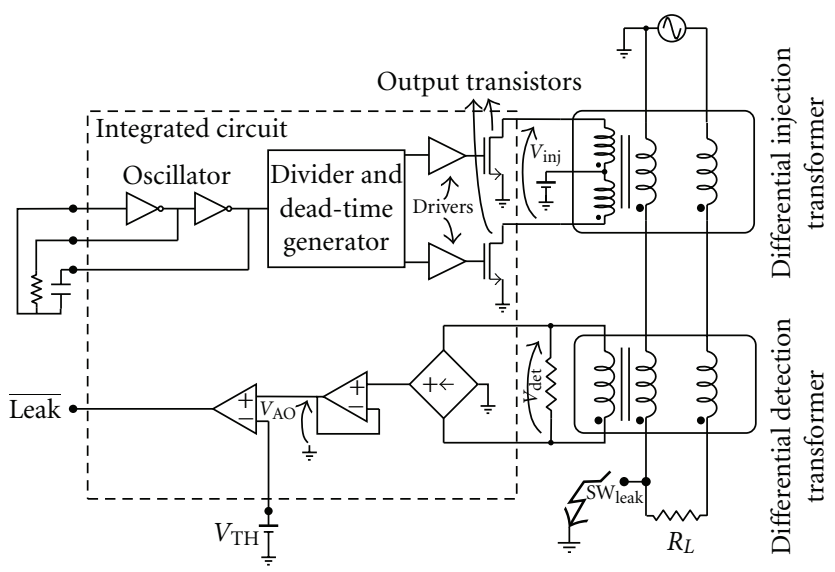

FIgURe 5: Simulated circuit.
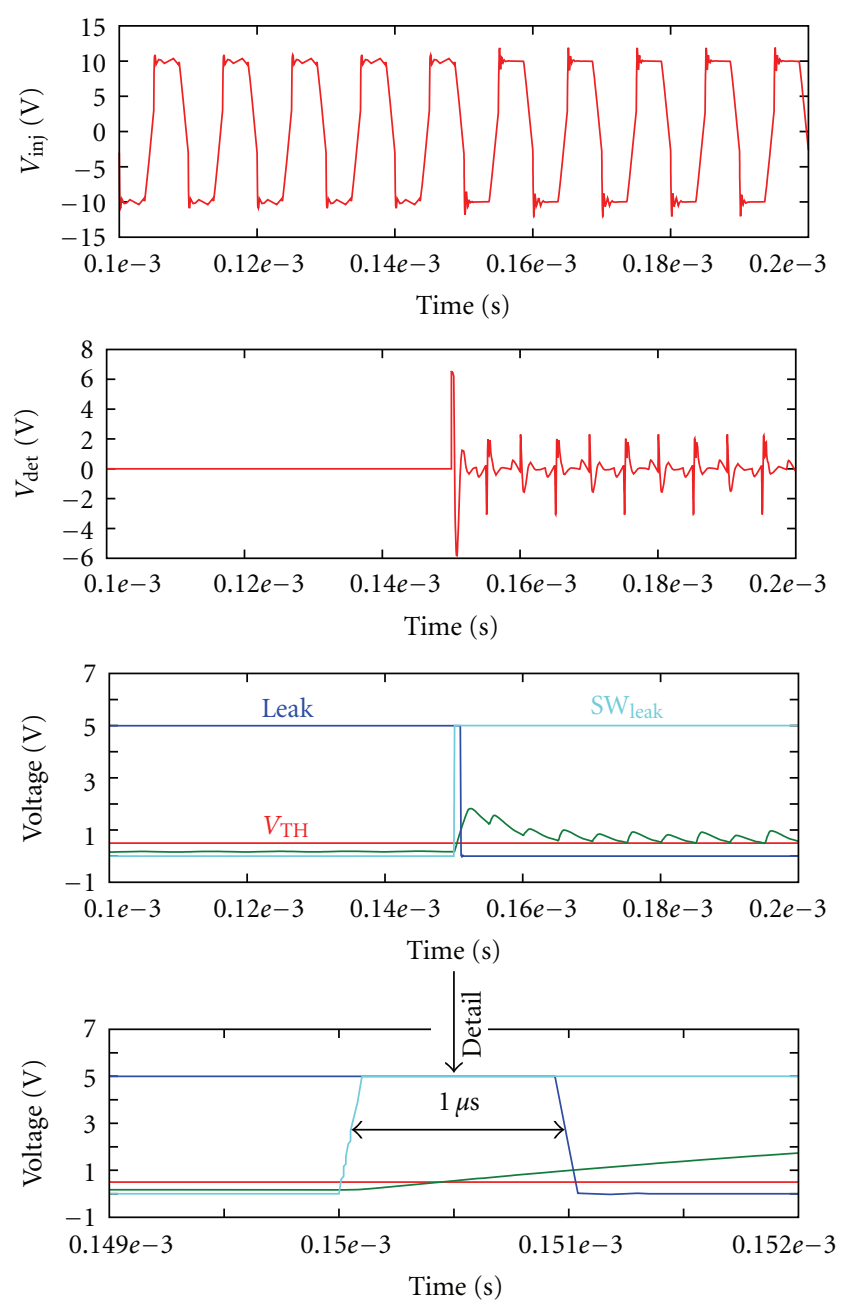

FIGURE 6: Simulation of an insulation fault.

and no voltage signal is induced at the detection transformer. When a failure occurs, the current is not zero anymore, and a signal appears at the detection transformer. If this signal is greater than the threshold after the amplification and filtering, the output of the comparator goes to a low level, indicating a failure condition.
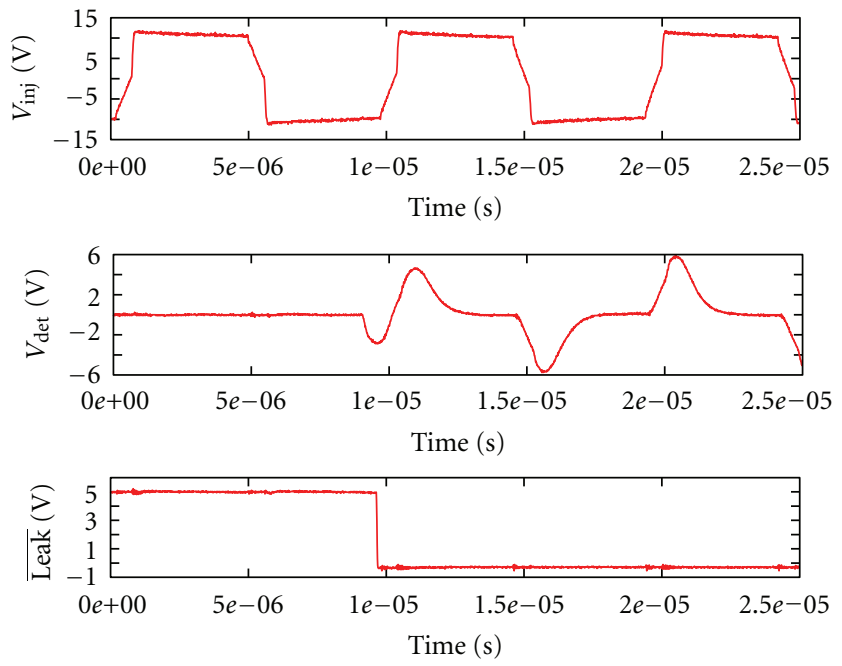

FIGURE 7: Oscilloscope capture of leakage fault.

The results of the simulation are displayed in Figure 6, where each voltage reference corresponds to those shown in Figure 5. The first two signals are the primary voltage of the injection transformer and the secondary voltage of the detection transformer. While the first signal is always present, the second one is only induced from the moment the simulated fault begins (at $0.15 \mathrm{~ms}$ ). The other signals plotted on Figure 6 show the detector performance: A delay of $1 \mu \mathrm{s}$ is measured from the moment $S W_{\text {leak }}$ is tripped to the time in which the output signal leak presents the lowlevel indication. This delay is shorter than that with other detection methods and could help not only protect humans from injury but also avoid the destruction of sensitive power devices.

2.5. Experimental Results. Firstly, in order to test the injector circuitry and the current and voltage capability of the integrated output transistors, the circuit was excited with a function generator. Then, it was easy to change the base-working frequency used to generate the command signals. The power transistors command signals were complementary and had the expected dead-time, matching with the simulations (not shown).

The output transistors were excited with these signals and connected to pull-up resistors to corroborate correct commutation and current rating. Transistors can successfully withstand $10 \mathrm{~V}$ during cut-off, which is the peak voltage that is generated in this push-pull configuration with the intended $5 \mathrm{~V}$ supply on the transformer's middlepoint. A current of approximately $300 \mathrm{~mA}$ through the output transistors was achieved. Hence, the output-stage can work from about $20 \mathrm{KHz}$ using high-frequency ferrite cores. Further testing proved the possibility of supplying the push-pull stage from up to $15 \mathrm{~V}$ with inductive loading (each transistor blocking $30 \mathrm{~V}$ ).

Secondly, the injection and detection scheme was tested with a bench similar to the one presented in Figure 5. The oscilloscope captures are shown in Figure 7. They show both 


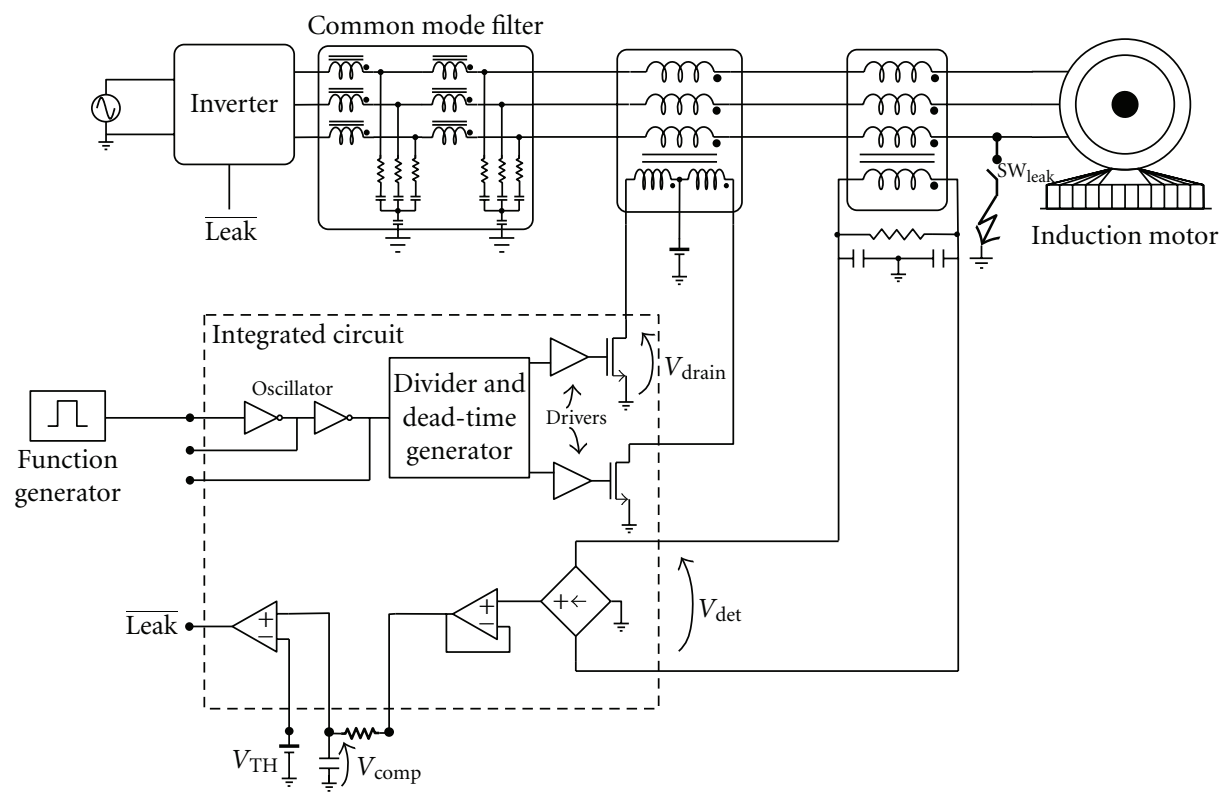

(a)

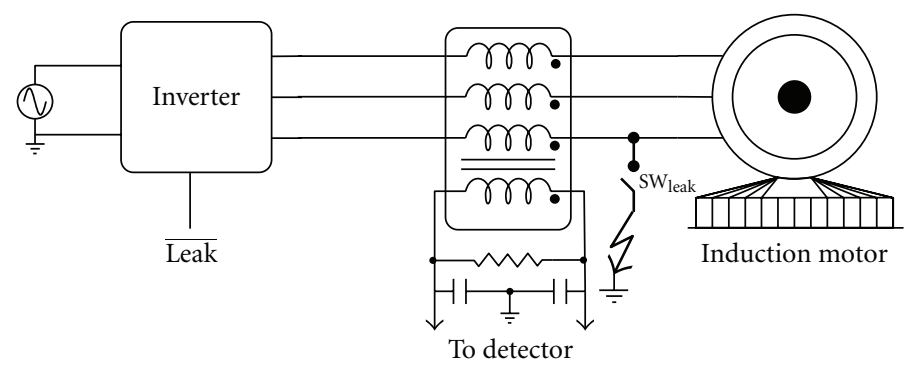

(b)

FIGURE 8: (a) Testbench for preventive offline protection and online protection. (b) Modified testbench for only online protection. The ground loop closes only when the inverter is on.

the injected and detected signals and prove the fast detection, with a delay of the order of $1 \mu \mathrm{s}$.

Even though this test was made with a single-phase resistive load, it is representative of the use of the designed PIC as fault to ground protection of generic polyphase circuitry with any kind of linear load and sinusoidal low frequency or DC supply voltage referenced to ground.

Finally, two additional tests were performed using the testbench shown in Figure 8 to show real life proofs. The simulated impedance leak consisted of a 22-ohm resistor in series with $4.7 \mathrm{nF}$ capacitor. The injected signal was configured to approximately $135 \mathrm{kHz}$. The comparator output was connected to the HITACHI X200-002SFEF inverter through the logic input that disables the turn-off.

The first test presents the use of the chip in an offline preventive application. The monitoring system detects a fault and avoids the turn-on of the inverter or drive system. In this case, the filter connected at the inverter output closes the ground loop. Both the injection and detection subsystems must be used. Figure 9 shows that the detection is accomplished within few microseconds with an adjusted threshold of $0.32 \mathrm{~V}$. In the final application a small three-phase RC network should be added at the inverter output to close the loop instead of the presented filter.

The second test shows the use of the detector as part of an inverter-fed system. In this case, the injector and filter are not needed because the motor is supplied by a PWM high-frequency signal as explained in Section 2. When the simulated fault condition appears and closes the ground loop, the PWM signal is detected as shown in Figure 10 and the inverter stops its operation. The threshold previously adjusted was kept for this oscilloscope capture but further tests without the filter showed that it should be increased to $3 \mathrm{~V}$ in order to avoid false positives.

\section{Future Work: Communications over the Power Lines of the Motor}

Another line of work which is currently under development is to use the components of the protection system to send and receive communication signals [13]. In this concept design, the power lines become a communication channel used for command and status signaling [18-20]. The advantage of 

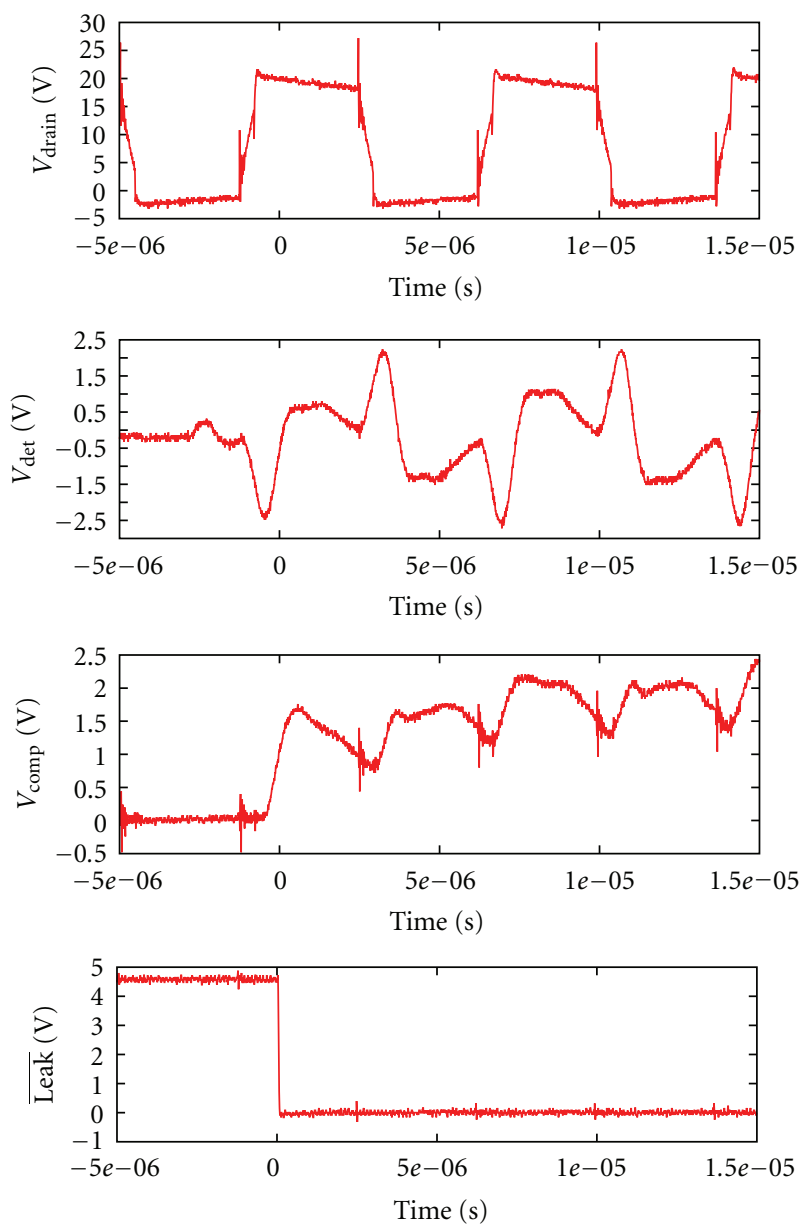

FIGURE 9: Scope captures of offline preventive detection.
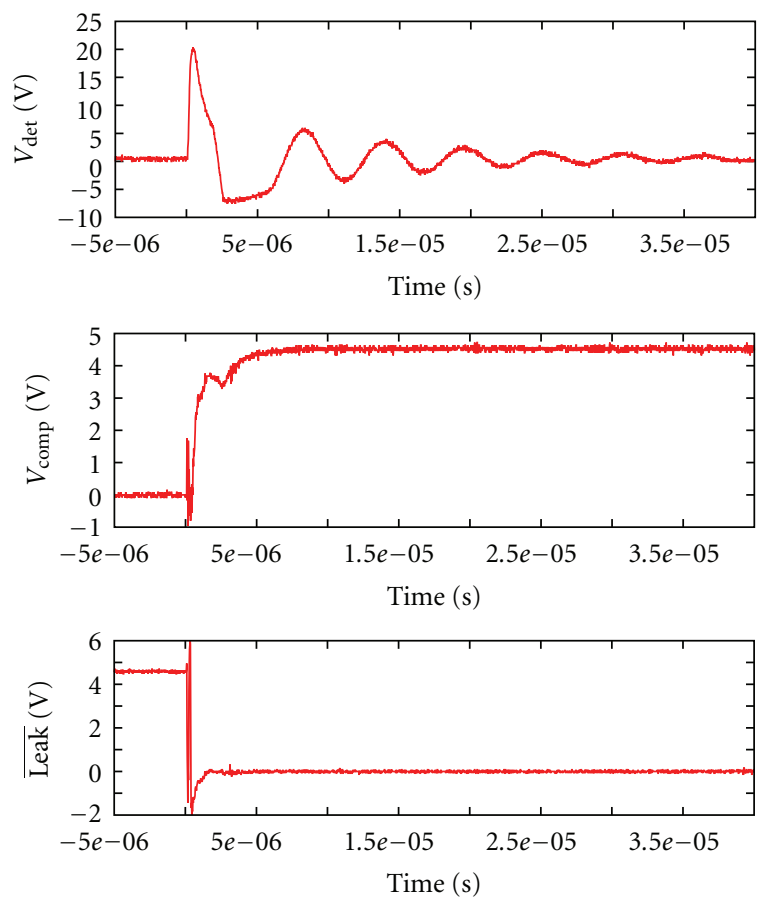

Figure 10: Scope captures of the online detection. 


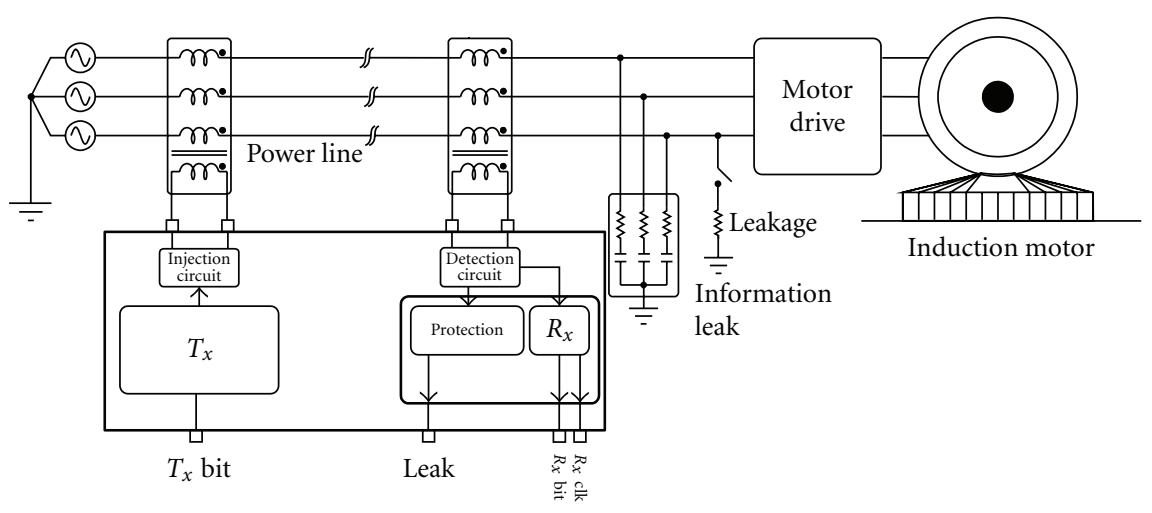

FIGURE 11: Communication and protection scheme.

this system is that no additional wiring is needed which usually makes it cheaper and easier to implement [18-21].

Figure 11 shows the general scheme used for the transmission (injection) and reception (detection) of commands in the power lines of the motor, where the signal injection is identical to the previous protection system. An FSK modulator produces the excitation signals with a frequency that depends on the information bit to send. On the other side, a conditioning circuit filters the detected signal and recovers the information injected in the motor power lines.

A proper design of the added RC networks (information leak) favors the existence of a communication channel without the presence of an insulation fault. The protection threshold should be carefully selected in order to continue providing a reliable protection.

A second version of the IC that implements the communication and protection functions is being developed.

\section{Conclusions}

The proposed differential scheme was validated with computed simulation and discrete experimental prototypes. Once the correct functioning of this protection scheme was verified, an integrated circuit was designed, sent to XFAB for fabrication, and then bonded and encapsulated by APTASIC.

The circuit proposed was extensively simulated and measurements were made to verify the output-stage ratings and the range of frequencies of the oscillator. All test benches proved a fast detection, with a delay of the order of a few microseconds. This delay is shorter than that with other detection methods but also avoids the destruction of electronic power devices.

While the application proposed in this paper is intended to protect electric motors and its control systems, this circuit is not limited to these devices. It can be used to protect regulators, matrix converters, power factor correctors, and even emergency power inverter systems.

Future test should be done and design procedures must be established to adjust the two comparator thresholds and transformers to avoid the destruction of sensitive power devices and at the same time protect humans from injury.

Finally, a new application of the integrated circuit was proposed not only capable of insulation fault detection but also able to send and receive command and diagnostic signals to the motors or devices connected to the power lines.

\section{Acknowledgments}

This work was made possible by the invaluable help of the IIIE at UNS, the DIE at UCU, and José Lipovetzky from the Microelectronics and Device Physics Laboratory at UBA. The authors would like to also thank Motortech S.A., Carlos Stahr of XFAB, Tanner EDA, and the people of APTASIC who very generously donated the packaging to the project.

\section{References}

[1] R. S. Navarro, Máquinas Eléctricas, McGraw-Hill, 1989.

[2] Rockwell Automation, "Basics for practical operation," Motor protection, 1997.

[3] R. Bayindir, I. Sefa, I. Colak, and A. Bektas, "Fault detection and protection of induction motors using sensors," IEEE Transactions on Energy Conversion, vol. 23, no. 3, pp. 734-741, 2008.

[4] A. H. Bonnett and G. C. Soukup, "Cause and analysis of stator and rotor failures in three-phase squirrel-cage induction motors," IEEE Transactions on Industry Applications, vol. 28, no. 4, pp. 921-937, 1992.

[5] M. Chafai, L. Refoufi, and H. Bentarzi, "Reliability assessment and improvement of large power induction motor winding insulation protection system using predictive analysis," WSEAS Transactions on Circuits and Systems, vol. 7, no. 4, pp. 184-193, 2008.

[6] Anon, "Report of large motor reliability survey of industrial and commercial installations, Part I," IEEE Transactions on Industry Applications, vol. 21, no. 4, pp. 853-864, 1985.

[7] Anon, "Report of large motor reliability survey of industrial and commercial installations, Part II," IEEE Transactions on Industry Applications, vol. 21, no. 4, pp. 865-872, 1985.

[8] S. B. Lee, J. Yang, J. Hong et al., "A new strategy for condition monitoring of adjustable speed induction machine drive systems," IEEE Transactions on Power Electronics, vol. 26, no. 2, pp. 389-398, 2011.

[9] F. Briz, M. W. Degner, P. García, and A. B. Diez, "High-frequency carrier-signal voltage selection for stator winding fault diagnosis in inverter-fed AC machines," IEEE Transactions on Industrial Electronics, vol. 55, no. 12, pp. 4181-4190, 2008. 
[10] K. Younsi, P. Neti, M. Shah et al., "On-line capacitance and dissipation factor monitoring of AC stator insulation," IEEE Transactions on Dielectrics and Electrical Insulation, vol. 17, no. 5, pp. 1441-1452, 2010.

[11] R. Arias, H. Mediote, and H. Tacca, "Flash FPGA-based numerical pulse-width modulator," Advances in Power Electronics, vol. 2011, Article ID 215376, 6 pages, 2011.

[12] H. Mediote, Aplicaciones de circuitos integrados programables al control de motores de inducción, thesis, Facultad de Ingeniería de la Universidad de Buenos Aires, 2008.

[13] M. F. Bulacio, Aplicaciones de circuitos FPGA al control de motores de inducción mediante comunicación a través de las líneas de alimentación, thesis, Facultad de Ingeniería de la Universidad de Buenos Aires, 2011.

[14] "Fairchild Semiconductor, RV4145A, Low Power Ground Fault Interrupter," Rev. 1.0.5, 2004.

[15] T. K. Chatterjee, D. K. Mittra, S. Mahata, and S. Kareddy, "A novel solid-state integrated protection system for three phase induction motors," in International Conference on Power Systems (ICPS '09), December 2009.

[16] IEEE Std C37.96-2000, "IEEE Guide for AC Motor Protection," Marzo 2000.

[17] I. Chatterjee, D. Wu, and O. P. Gandhi, "Human body impedance and threshold currents for perception and pain for contact hazard analysis in the VLF-MF band," IEEE Transactions on Biomedical Engineering, vol. 33, no. 5, pp. 486-494, 1986.

[18] A. Kosonen, M. Jokinen, J. Ahola, M. Niemelä, and J. Toukonen, "Ethernet-based broadband power line communication between motor and inverter," IET Electric Power Applications, vol. 2, no. 5, pp. 316-324, 2008.

[19] N. Ginot, M. A. Mannah, C. Batard, and M. MacHmoum, "Application of power line communication for data transmission over PWM network," IEEE Transactions on Smart Grid, vol. 1, no. 2, pp. 178-185, 2010.

[20] A. Kosonen and J. Ahola, "Communication concept for sensors at an inverter-fed electric motor utilizing power-line communication and energy harvesting," IEEE Transactions on Power Delivery, vol. 25, no. 4, pp. 2406-2413, 2010.

[21] T. Brooks, "Wireless technology for industrial sensor and control networks," in Proceedings of the ISA/EEE Sensors for Industry Conference, pp. 73-77, Rosemont, Ill, USA, November 2001. 

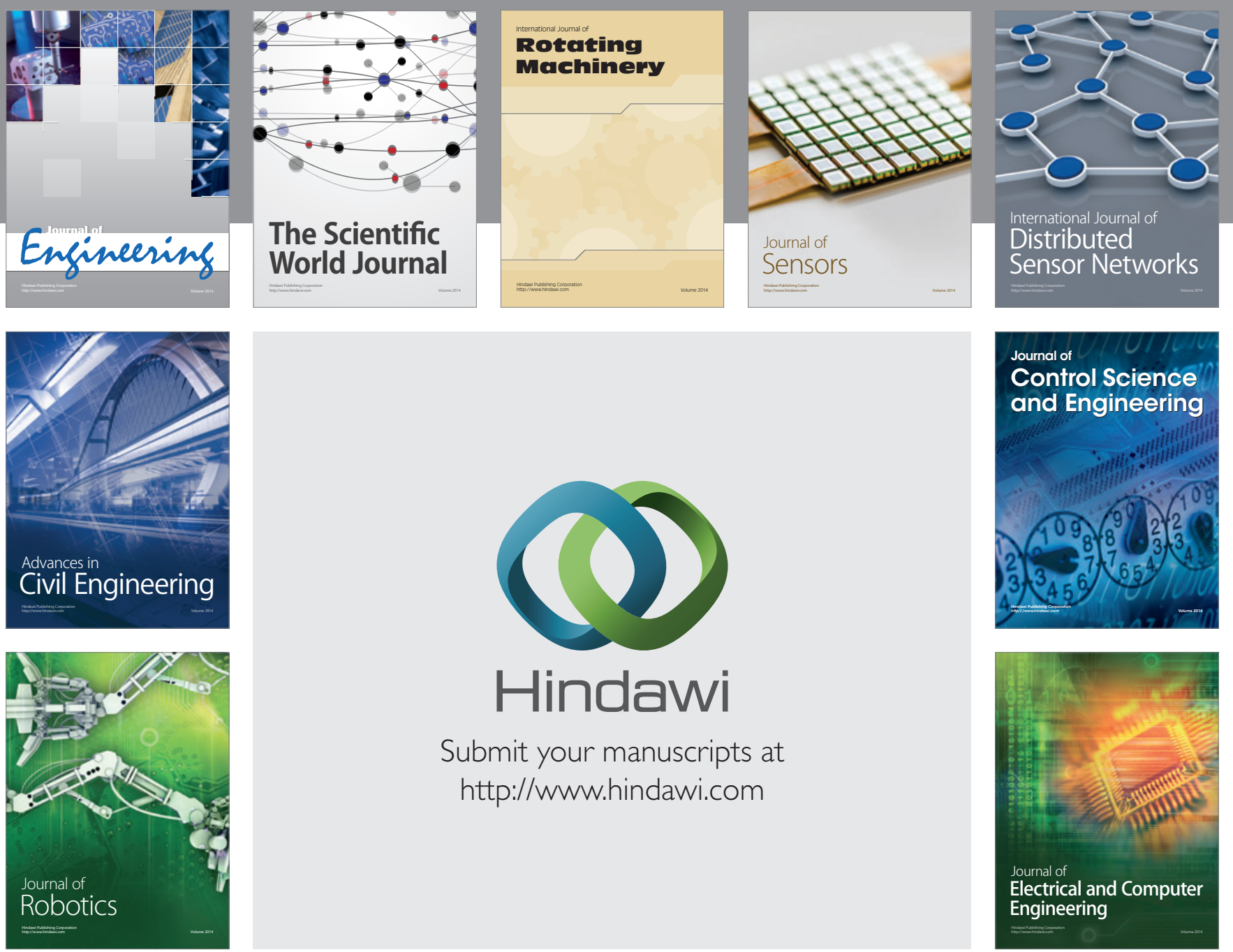

Submit your manuscripts at

http://www.hindawi.com
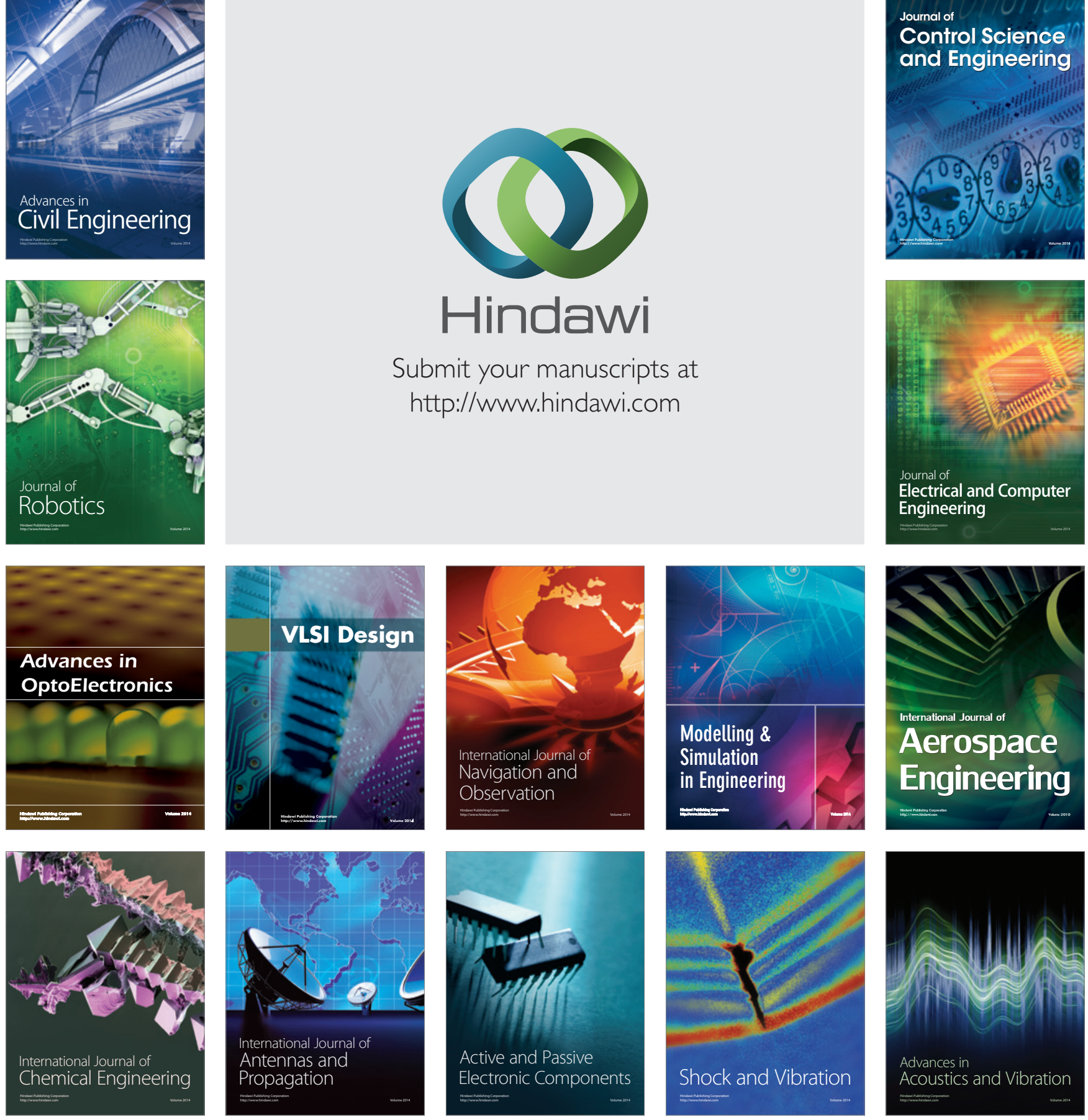